\title{
Influence of Psychological Factors on Pain and Disability in Anterior Knee Pain Patients
}

Julio Doménech, Vicente Sanchis-Alfonso,

and Begoña Espejo

\subsection{Introduction}

Pain is a constant symptom in patients with a Patellofemoral Syndrome (PFS). The definition proposed by the International Association for the Study of Pain establishes pain as "an unpleasant sensory and emotional experience associated with actual or potential tissue damage, or described in terms of such damage." ${ }^{\prime 7}$ This definition establishes the experience of pain in a subjective manner unmatched with a measurable external stimulus. Meaning, it is a prerogative of the subject itself suffering the pain that determines if pain is present or not, regardless of any objective structural damage.

Melzack and Casey ${ }^{82}$ proposed structuring pain in three dimensions: (1) Sensory-discriminative. It refers purely to the sensitive magnitude of pain, with which we can determine three related elements: its location, its intensity, and its quality; (2) Affective-motivational. It refers to the emotional properties that accompany the painful feeling such as fear (or anxiety), sadness (or depression), rage, or anger that facilitate or predispose for a response such as aversion, escape, avoidance, or fight; (3) Cognitive-evaluative. It refers to beliefs, thoughts, attitudes and coping strategies regarding pain, the consequences of the experience of pain, and the possible design of a conscious plan to handle the situation.

According to Melzack, ${ }^{81}$ these categories interact with one another and influence each other, and can only be understood as a whole. In most cases, there is a high correlation between the sensory and affective

\footnotetext{
J. Doménech $(\bowtie)$

Department of Orthopaedic Surgery, School of Medicine, Catholic University of Valencia, Valencia, Spain e-mail: julio.domenech@ucv.es
}

dimensions, whereas when pain is more intense, it feels more uncomfortable and causes stronger avoidance and escape reactions. The effects between emotional and cognitive factors in the perception of pain are also known..$^{59,62,77,79}$ Traditionally, pain has been related to the disability that the person with a lesion suffers. This correlation is very strong in acute pain. For example, a patient with an acute patellar lesion experiences acute pain, limiting his mobility and disabling him for his ordinary activities. However, pain that becomes chronic can hardly be attributed to identifiable physiologic damage. Pain, impairment, and disability are related but are independent constructs with no connection at all. ${ }^{37,127}$

This correlation between chronic pain and disability is also found in chronic patients with PFS. Jensen et al..$^{50}$ studied a group of patients with PFS measuring the degree of pain with the VAS scale and the disability with the Cincinnati Knee rating system (CKRS) questionnaire, and found no significant correlation between the level of pain and the measured disability (Pearson $r=0.33, p$ not significant). In another study by our research group, a significant correlation between pain and disability measured with the Lysholm questionnaire was found, but with a poor correlation index. ${ }^{21} \mathrm{In}$ another study of young women with PFS, no significant differences were found in the level of functional activity between patients with more knee symptoms and less symptomatic patients. ${ }^{116}$ Therefore, we can reason that PFS causes, on one hand, pain and on the other hand, disability; being both independent dimensions with a poor correlation.

For more than a century, the treatment of musculoskeletal conditions has been based on a biomedical disease model ${ }^{65,122}$ This model establishes a direct and sequential relation between tissue damage and pain, between pain and functional impairment and 


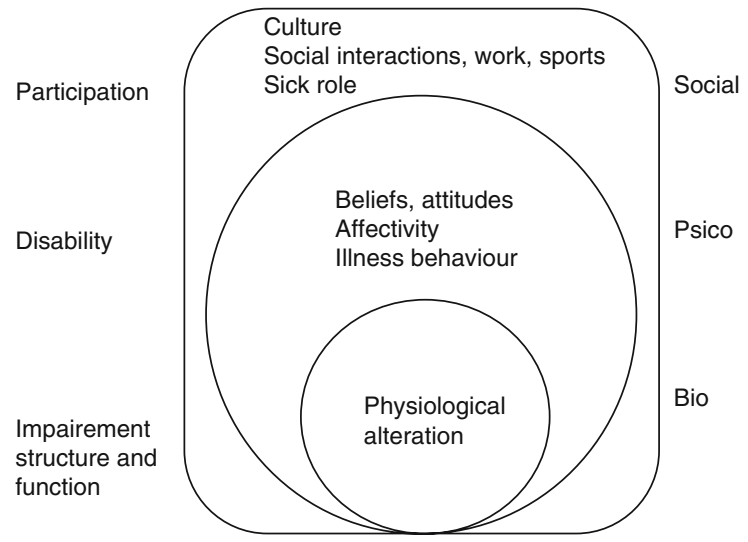

Fig. 9.1 The Biopsychosocial model of chronic pain and disability. ICF International Classification of Functioning Disability and Health, WHO World Health Organization (Modified from Waddell ${ }^{127}$ )

disability. Therefore, the doctor's task would be to repair the damage and clear the pain, making the functional impairment and disability disappear. This model has worked well for conditions such as meniscal tears. However, for some conditions that develop with chronic pain, such as low back pain, this classical model is not enough to establish an adequate treatment. ${ }^{25,36,127}$ In these cases, a psychosocial model that integrates patient's biological, psychological, and social elements would be more useful (Fig. 9.1).

In patients with anterior knee pain syndrome (AKPS), the biomedical model, which is very important in understanding the pathophysiology and determining adequate treatment, does not completely explain certain clinical findings. As an example, patients with AKP show different degrees of disability in their everyday life, regardless of how intense the pain is. ${ }^{21,50}$ Furthermore, no significant correlation between structural alterations of the patellofemoral joint and disability have been observed..$^{45,97,116}$ In fact, some cases with important anatomic alterations (patellofemoral malalignment, severe patellar chondropathy) are painless..$^{51,74}$

The biopsychosocial model would allow the development of more adequate therapeutic strategies than the biomedical model..$^{9,25,36}$ Nowadays, very few studies focus on the patient with AKP from a biologic, psychological, and social perspective, although for other conditions such as low back pain, knee osteoarthritis, fibromyalgia, or rheumatoid arthritis, many studies focus on their treatment from this perspective..$^{5,26,52,113}$

\subsection{Fear-Avoidance Model in Musculoskeletal Pain}

In the beginning of the 1980s, several authors proposed the Fear-Avoidance Model ${ }^{69,93,124,125,128}$ (Fig. 9.2). This model was initially developed for patients with low back pain and wanted to explain why most of the patients that suffered an episode of acute low back pain resolved spontaneously while a minority of patients developed chronic low back pain. This fear-avoidance model established the existence of many possible responses to a lesion that causes pain. Those patients who do not perceive pain as a threat and are able to cope with it satisfactorily continue their usual activities and achieve full recovery. On the other hand, patients who interpret pain in an exaggerated or catastrophic way develop fear to pain and associated behaviors in search of security, such as hypervigilance and avoidance. Although these avoidance and hypervigilance behaviors can be adaptive when coping with acute pain, they can worsen the patient's condition if the pain is chronic, because they favor disuse, depression, and increase disability. In later years, Asmudson ${ }^{4}$ added the pain anxiety component to this model as an aggravating factor in the avoidance behavior generating circuit. The avoidance behavior would not only include limiting the movements, but also avoiding social interactions and recreational activities, which increase pain and suffering in patients. ${ }^{68}$ Crombez $^{18}$ has even said that "the fear of pain is more disabling that pain itself."

In many crossover studies, fear and avoidance behaviors have been strongly associated with the disability present in patients with low back pain. . $^{1,59,128,134}$ Also, in low back pain longitudinal studies, changes in the fear avoidance beliefs were good disability predictors. ${ }^{14,33,39,43,115,135}$ The fear of pain and the catastrophic vision of pain also occur in pain-free people, so these beliefs can play an important role in the development of new episodes of pain. In studies performed in subjects without low back pain, ${ }^{49,71,72,120}$ it was observed that fear of pain increased the risk of suffering episodes of low back pain, and therefore the risk of a disability was increased. Picavet ${ }^{94}$ performed a longitudinal study in a population of 1,571 subjects without any important illness during 6 months. The results showed that for the group that indicated the initial low back pain, catastrophization 
Fig. 9.2 The fear-avoidance model of chronic pain based on the fear-avoidance model of Vlaeyen and Linton ${ }^{125}$ and the fear-anxiety-avoidance model of Asmudson et al. ${ }^{4}$

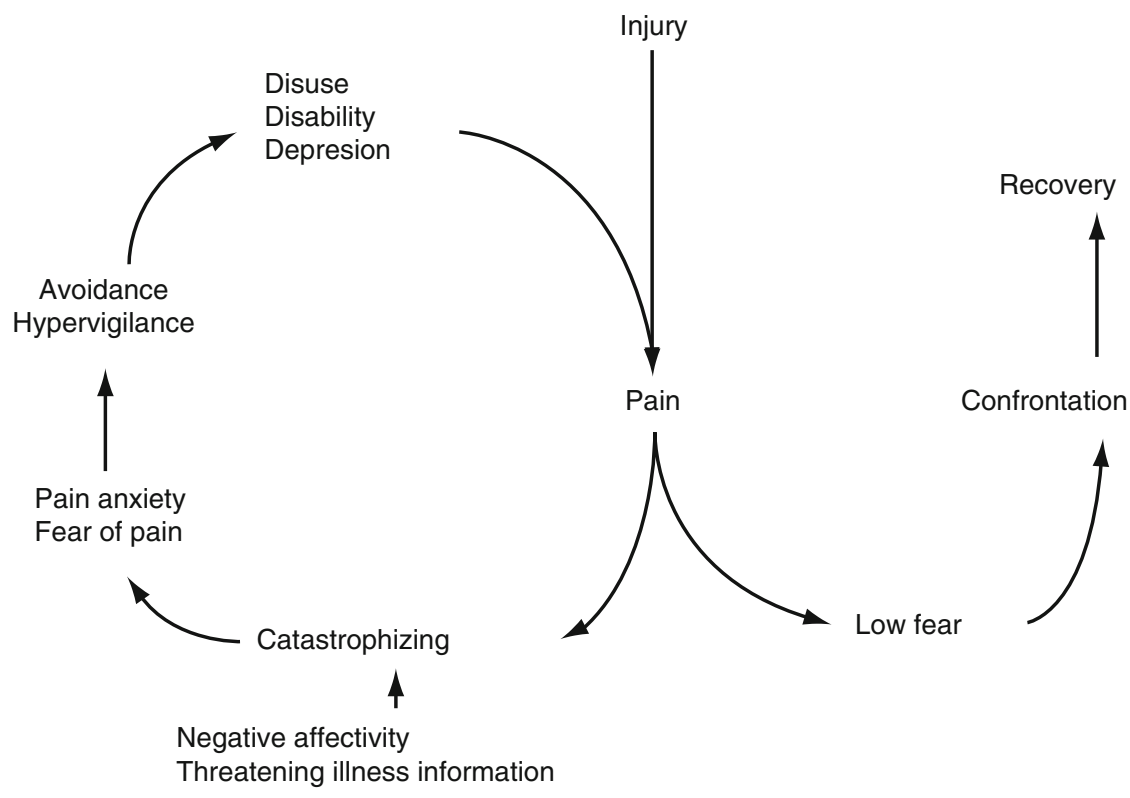

and kinesiophobia were good predictors for the chronification of pain and the disability. Interestingly, in those subjects with no initial low back pain, both catastrophization and kinesiophobia, also predicted low back pain with disability during follow-up. In another study, Carragee ${ }^{14}$ performed a 5 year followup in a group of 100 subjects with mild low back pain, by performing magnetic resonance imaging (MRI) and a discography, measuring their fearavoidance beliefs with a FABQ (Fear Avoidance Beliefs Questionnaire). Surprisingly, the severe low back pain cases and disabilities had no relation with structural anomalies found in the MRI or discography, and it was the presence of fear and avoidance behaviors that turned out to be the strongest predictor in low back pain and disability.

The AKP syndrome shares with nonspecific low back pain the fact that both conditions have a low correlation between the symptoms and anomalies found in imaging studies, and both conditions tend to become chronic and cause disability. Piva ${ }^{98}$ studied to see if changes in the fear-avoidance behaviors (measured in the FABQ modified for the knee) influenced the disability in a group of patients with AKP under conventional physical therapy treatment. They found that those patients who lowered their levels of fear and avoidance of physical activity and work, improved their level of pain and disability at the end of the treatment.
In research done by our study group, ${ }^{21} 54$ patients with AKP longer than a year and with severe pain were analyzed (6.3 mean in the Visual Analog Pain Scale). The ideas of fear and avoidance measured with the Tampa Kinesiophobia Scale showed a strong correlation with the patient's referred disability measured with the Lysholm score $(r=-0.59, p<0.001)$; therefore, the greater the fear and avoidance beliefs, even greater will the disability perceived by the patient be. It is interesting to highlight that the correlation between kinesiophobia and disability was higher than the one between pain and disability. These patients also had very strong catastrophizing ideas measured through the Catastrophizing Coping Scale Questionnaire and through the catastrophic imaging subscale of the Coping Strategies Questionnaire. These beliefs also showed a statistically significant correlation with the disability $(r=-0.49$, $p<0.001$ ), when the perception of pain is more catastrophic, the patients perceive a higher disability.

Several studies have shown that cognitivebehavioral treatments focused on reducing these fearavoidance behaviors and the catastrophization of pain, influencing the clinical state of patients with chronic osteoarticular pain in a positive manner. ${ }^{103,109,114}$ This approach opens the doors for the trial of new treatment models integrating the biopsychosocial model. Therefore, psychologic therapies can work together with physical therapy and surgical therapies in AKP patients. 


\subsection{Relationship Between Cognitions and Anterior Knee Pain}

\subsubsection{Coping Strategies}

In the last decades, the concept of coping with pain has become one of the most important aspects in understanding the consequences of chronic pain in the patient's health. Coping has been defined as the constantly changing cognitive and behavioral efforts that are developed to deal with specific external and/or internal demands evaluated as going beyond the individual's resources. ${ }^{66}$ In the case of chronic pain, the patients see their pain as a source of stress for which they develop cognitive and behavioral strategies that are constantly changing to minimize the impact of pain and disability. On certain occasions, these coping strategies are positive, improving tolerance to reduce the perception of pain and disability. But on other occasions, these coping strategies are not adaptative, worsening the disease's clinical course. These differences in managing pain influence the compliance to the treatment prescribed by the doctor.

The Coping Strategies Questionnaire (CSQ) ${ }^{99}$ has been widely used in patients with rheumatic conditions. This tool measures the frequency with which patients use different coping strategies. It is comprised of seven subscales, six cognitive (distraction, reinterpreting the painful feeling, ignoring the feeling of pain, coping self-assertion, prayer or hope, and catastrophic view), and a behavioral subscale (increase in the activity level and the behaviors that reduce the painful feeling).

Several studies have shown that patients with osteoarthritis of the knee and arthritis that have high scores in the Pain Control and Rational Thinking factors and low scores in the cognitive distortion factors (catastrophization), show low levels of disability, pain and psychological distress, as well as less behaviors associated with pain. ${ }^{55,56,58,87,131}$ Another approach to understand the pain-coping strategies is provided by the Vanderbilt Pain Management Inventory (VPMI), which divides the strategies into passive and active. ${ }^{10}$ The active strategies are those in which the patient is actively involved in the management of his pain, such as entertainment with other recreational activities, practicing sports, or keeping up with his daily activities. In the passive strategies, the patient leaves his pain in the hands of the doctor, talks frequently about his pain or uses medication to achieve instant relief. Passive strategies are associated with a significant increase in the risk of developing chronic pain, depression, and physical disability in several studies of patients with arthritis, osteoarthritis, and low back pain..$^{83,90}$

Thomeé ${ }^{116}$ studied the coping strategies in a group of 50 Swedish patients with chronic AKP using the CSQ questionnaire, and found that the scores in the different coping subscales were in accordance with the results published in other series of patients with other aetiologies of chronic pain. The most commonly used strategy was the coping self-statements and the less used was reinterpreting pain sensations. In a recent study done by our group in Spain, in a 54 patient group with chronic AKP, similar results were found regarding the frequency with which the different coping strategies are used, regardless of the cultural differences between people of the different studies. The most used strategies were the increase in behavioral activities and the coping self-statements, and the least used was reinterpreting pain sensations. The strategies that showed the highest variability among patients were the catastrophic vision and the coping self-statements. ${ }^{21}$ In this study, we also analyzed the relationship between the pain-coping subscales and pain and disability. The catastrophic vision and prayer/hope subscales showed significant correlation with the patient's disability. Also, all of the coping strategies except the prayer/ hope one had a significant relationship with the HAD. However, none of the coping strategies showed a significant relationship with the degree of pain.

The modification of the beliefs and behaviors of the patients, in order to use more adequate pain-coping strategies, can help them reduce their symptoms, increase their functional capacity, and reduce their psychological distress. Some clinical trials have shown that a cognitive-behavioral treatment combined with the usual medical treatment in patients with chronic rheumatoid pain is useful in improving their physical and psychological state. ${ }^{26,31,102}$

\subsubsection{Catastrophization}

The catastrophic vision of pain refers to the cognitive process by which pain is seen as an extreme threat and from which the patient suffers exaggerated negative consequences. There is growing evidence that the 
catastrophic vision of pain is related not only to the pain the patients mention but also to other aspects that influence the course of the illness. Some studies show that patients with musculoskeletal pain with these ideas have a higher degree of disability ${ }^{78}$ higher use of health resources, ${ }^{100}$ higher use of medication, ${ }^{7,48}$ and worse recovery after knee arthroplasty surgery. ${ }^{60}$

Many studies confirm a strong association between the ideas of pain catastrophization and the patient's disability in several conditions with chronic pain mainly in musculoskeletal pain..$^{92,101,112,118}$

Besides the association with disability, the catastrophic view has been related to the degree of pain. Patients with important ideas of catastrophization mentioned higher degrees of pain, both in acute and chronic pain conditions. ${ }^{11,100,101,118}$ Follow-up studies have also shown that the initial catastrophization ideas are related to the level of pain that a patient will point out after a surgical procedure ${ }^{41,88}$ or after other painful conditions. . $23,24,11,126^{2}$

Although the exact mechanisms by which catastrophization affects the experience of pain and disability are not well known, it has been suggested that it influences the focusing of one's attention to the painful or potentially painful process. People, who catastrophize, have difficulties in not focusing on the painful or threatening stimulus. ${ }^{17,91}$ This intensifies fear of pain, which increases attention paid to the stimulus. Therefore, evaluating a threat, regardless of the degree of pain, is an important mediator in the perception of pain. Also, an excessively emotional evaluation of pain is associated with catastrophization, which produces a higher perception of the experience of pain. ${ }^{38}$ In a study done with functional MRI in patients with chronic pain, it was seen that ideas of catastrophization were not only associated with a higher degree of activity in the brain's pain processing areas but also in the cortical areas related to attention, the anticipation of pain, and emotional aspects of pain. ${ }^{40}$ In a study performed in healthy subjects in whom pain was caused by heat, higher levels of pain catastrophization were related with a higher degree of pain as well as higher duration of the heat-related pain. This suggests that catastrophization plays a facilitator role in the pain perception process. ${ }^{23}$

Catastrophization can be clinically measured by the catastrophization subscale of the Coping Strategies Questionnaire (CSQ). ${ }^{99}$ There is another specific tool to measure it as well, the Pain Catastrophizing Scale
(PCS). ${ }^{110}$ This questionnaire has been widely used in clinical practice and has excellent psychometric features.

Even if the influence of the catastrophic view in chronic pain and disability has been widely studied in musculoskeletal conditions such as rheumatoid arthritis,,$^{53,57}$ knee osteoarthritis ${ }^{30,55,107}$ or low back pain, ${ }^{17,84,92}$ we are only aware of two studies that analyze this aspect in the AKP patient. Thomeé ${ }^{117}$ studied the paincoping strategies in a group of AKP patients. The catastrophization subscale showed a very high score in the patients with AKP, more than double the score found in other series of rheumatoid arthritis patients. Our group studied the relationship between the catastrophization ideas (measured with the catastrophization subscale of the CSP, and also specifically with the PCS questionnaire) and the disability in a group of patients with AKP. A statistically significant correlation was found between the disability Lysholm scale score and the score obtained from the PCS questionnaire ( $r=-0.49 ; p=0.001)$; however, there was poorer correlation with the degree of pain $(r=0.32 ; p=0.023) .^{21}$ In this study, we also found that catastrophization was a widely used coping strategy in chronic AKP patients.

\subsection{Relationship Between Depression and Anterior Knee Pain}

Depression is a psychopathologic condition that has been frequently associated with chronic pain. The prevalence of depression in chronic musculoskeletal pain patients is higher than in the general population. Applying strict diagnostic criteria, the prevalence of depression varies between $30 \%$ and $60 \%$ in chronic pain patients, ${ }^{20,76}$ while in the pain-free general population, it is between $2 \%$ and $4 \% .80$

The importance of this association lies in the fact that both conditions, chronic pain and depression, can interact to intensify their effects. A meta-analysis of 83 studies has shown that the severity of the depression is related not only to the presence of chronic pain, but also to its duration, the degree of pain, and the number of painful areas. ${ }^{28}$ Regarding its influence on the disability, several studies show that depression reduces the functional capacity of patients with osteoarthritis and rheumatoid arthritis. ${ }^{6,62,89}$ Furthermore, in patients with depression 
and chronic pain, if the pain is reduced, the depression symptoms improve. ${ }^{28,63,130}$ The relationship between depression and pain is reinforced by the fact that antidepressant drugs have an analgesic effect in musculoskeletal pain patients even without depression. ${ }^{108}$

Even if the relationship between chronic pain and depression has been widely studied in other musculoskeletal conditions, very few studies analyze this relationship in AKP patients. Carlsson ${ }^{13}$ used the Rorschach test in a group of patients with AKP comparing it to a control group. Patients with AKP were different than control patients in that they showed a higher depression index (DEPI $>4)$. Comparison with a group of psychiatric outpatients showed a higher depression rate in patients with AKP. However, Witonski ${ }^{132}$ using the Beck Depression Inventory (BDI), found no differences between a group of 20 AKP patients with a mean age of 18 and a control group of similar age. It is possible that the difference in the results is because this last group was too young, a mean age of 18 , or else because of the different type of measurement tool. Clark ${ }^{15}$ performed a clinical trial with 81 AKP patients, assigning them randomly to four types of physical therapy treatments. Prior to this treatment, $15 \%$ of patients had borderline depression symptoms or a well-established depression measured with the Hospital Anxiety and Depression questionnaire (HAD) scale. Interestingly, the levels of depression, pain, and disability improved after 3 months and after 12 months of treatment in the four groups.

In a crossover study done by our research group, we analyzed a sample of 54 patients with chronic AKP. ${ }^{21}$ We measured the presence of depression symptoms with the HAD questionnaire. $46.3 \%$ of our patients had a score equal or higher than 11 , which is an indication of a confirmed clinical illness, ${ }^{136}$ while the rest of the patients, except one, had a score of clinical suspicion of depression.

Therefore, in a chronic AKP patient, it is important to identify the coincidence of a depression for several reasons. The most important is that a depression increases the disability and the degree of pain and, therefore, perpetuates the condition. Another reason is that the undiagnosed and untreated depression has been related to a poor response to physical therapy or surgery. It is essential to perform a special evaluation aimed at ruling out the coexistence of a hidden depression in these patients.

\subsection{Relationship Between Anxiety/ Stress and Anterior Knee Pain}

Anxiety and stress are normal emotional reactions regarding certain situations. Both anxiety and stress in a mild or moderate form are healthy and even beneficial because they motivate a person to prepare a response, either to remain vigilant or to serve as a warning when in danger. However, on occasions, it becomes dysfunctional when its level is too high or lasts too long, becoming pathological.

Anxiety expresses itself differently in patients, sometimes in emotional and cognitive manners (tension, fear, edginess, discomfort, nervousness), behavioral or motor aspects (immobility, avoidance, restlessness); however, on occasion, it is accompanied by vegetative reactions such as perspiration, palpitations, dry mouth, shaking, dizziness, or nausea.

Patients with chronic pain perceive pain as a situation that generates prolonged stress. The prevalence of anxiety in patients with chronic pain is very high. ${ }^{80}$ The presence of anxiety influences the symptoms in these patients bidirectionally. High degrees of pain can sometimes predict anxiety symptoms ${ }^{106}$ and conversely, anxiety increases the painful experience. ${ }^{121}$ One of the most studied mechanisms of the effects of maladaptative anxiety in chronic pain patients is a tendency toward hypervigilance and catastrophization. ${ }^{4}$ These tendencies amplify the perception of pain and cause behaviors that increase disability. ${ }^{79}$

Clark $^{15}$ found that $27 \%$ of patients with AKP who were included in a clinical trial showed anxiety symptoms measured with the HAD questionnaire, and after receiving treatment these symptoms improved. Thomeé ${ }^{117}$ also found high levels of anxiety in a group of patients with AKP, using the STAI questionnaire (State Trait Anxiety Inventory), finding similar scores to those published for rheumatoid arthritis. Carlsson ${ }^{13}$ measured distress/anxiety using the Rorschach test in patients with AKP and in a control group mainly of physical therapy students, finding out that patients had a high anxiety level, but with no difference from the control group. The authors will probably comment to say that this is because the students also have a high level of distress. Piva ${ }^{98}$ studied a group of AKP patients with at least 4 weeks of pain and an average numeric scale pain of 3.6, finding a correlation with the disability and the level of anxiety measured with the Beck questionnaire, 
suggesting that patients with more limitations in physical function had higher anxiety levels.

In a study conducted by our working group in chronic AKP patients with important symptoms (mean VAS 6.3 and Lysholm score 50), high anxiety levels measured through the HAD questionnaire was present in $90 \%$ of patients, and above the level, considered the diagnosis of anxiety disorder in $37 \%$ of the cases. However, although no correlation between anxiety with pain or disability was found, a very significant correlation between kinesiophobia (fear of movement) and disability was found. ${ }^{21}$

Even if anxiety is often present in patients with chronic pain, its role in disability seems to be more related to fear. Fear and anxiety go hand in hand but are not the same thing. Anxiety is an emotional reaction to something undetermined, while in fear the threat is specific. In patients with chronic pain, fear appears as fear to pain and fear to movement, which can cause the pain and worsen the lesion. ${ }^{68}$ Even so, anxiety itself worsens the suffering of these patients, as an entity by itself and deserves to be treated.

\subsection{Relationship Between Personality, Mental Disorder and Anterior Knee Pain}

The prevalence of mental disorders is higher in patients with chronic pain than in the general population. ${ }^{20}$ However and despite the fact that it is a common idea in orthopedics, there seem to be no studies that support the existence of a psychopathic personality or other mental health conditions that predispose for AKP.

In a prospective study, Gatchel ${ }^{37}$ evaluated the predictive value of a battery of mental health parameters in a large group of patients with acute low back pain to determine who would develop disability in the long term because of chronic pain. This study did not find any predictive capacity for major psychopathology in the development of disability caused by chronic pain. These findings suggest that although an association between psychopathology and chronic pain exists, we cannot state that psychopathologic conditions cause chronic pain, but they are rather a consequence of it. Other findings support this, since the incidence of psychological conditions is higher in patients with chronic musculoskeletal pain. ${ }^{35,61,95}$ Furthermore, Dersh ${ }^{20}$ studied the presence of psychiatric conditions in a group of 1,595 patients with chronic pain and disability caused by different musculoskekeletal conditions, finding that $64 \%$ had a psychiatric condition, compared with $15 \%$ in the general population. However, he found that this high incidence appeared only after the onset of the musculoskeletal process, suggesting that the stress associated with pain was a determining factor in the intensification of it. Some studies have found that the incidence of psychiatric conditions is lower in musculoskeletal pain patients after an effective physical therapy treatment of their condition. ${ }^{86,123}$ In a study with 250 chronic pain patients, it was shown that personality traits and initial personality disorders were not useful to predict disability after 1 year. ${ }^{70}$ In another study performed with patients that suffered different musculoskeletal conditions and healthy patients, it was shown that the differences in the different personality traits had a stronger correlation with psychological distress than with pain. ${ }^{75}$

AKP patients have been thought of as having a neurotic personality that predisposed them to suffer from chronic pain without structural damage. Some authors believe that when no structural causes are found, the condition could be explained by psychological problems (family, self-esteem, sport performance, aversion to sports). ${ }^{19}$ Witonski ${ }^{132}$ states that AKP could be a psychosomatic condition after finding personality disorders in these patients following the Minnesota Multiphasic Personality Inventory (MMPI) questionnaire. This questionnaire, however, has been questioned for its use with patients with rheumatic conditions, suggesting it should be used with caution in rheumatic patients. ${ }^{27,54}$ High levels of depression, hypochondria, and hysteria measured by the MMPI reflect the level of arthritis better than the psychological status. ${ }^{96}$ In patients who were operated on because of low back pain, high levels of psychopathology using MMPI were found; however, in an epidemiological study done in those patients on whom by chance the MMPI was used prior to the condition, the premorbid profiles were normal, which is a strong suggestion that the disease causing the chronic pain is responsible for the personality trait changes. ${ }^{44,73}$

Witvrow ${ }^{133}$ studied a group of 282 asymptomatic student athletes that were followed for a 2 year period. At the beginning of the study, the student's psychological features were studied. At the end of the study, 24 patients developed AKP. Solely, the parameter 
"looking for social support" obtained a significant lower score in the group with pain compared with the control group, but no difference was found in neurotic and psychosomatic instability, extroversion, palliative reaction, passive reaction pattern, expression of emotions or reassuring thoughts. Studies analyzing personality traits in patients with established AKP have been performed. Fritz ${ }^{32}$ did a prospective study in a group of 28 adolescents with AKP through the High School Personality Questionnaire (HSPQ) before evaluating the cause of their pain. The goal of the study was to verify the usefulness of this questionnaire in order to identify patients with a structural identifiable cause. After an 8 month follow-up, one third of the patients showed psychological factors associated with pain, but the personality questionnaire was not useful to differentiate between the structural cause group and the functional cause group. In another crossover study, Carlsson ${ }^{13}$ found no alexithymic personality traits in a group of AKP patients, although patients with chronic pain did show higher levels of depression, hostility, and passive attitudes than the control group.

From the different studies to investigate the influence of personality both in chronic musculoskeletal pain and specifically in AKP patients, there is no causal relationship between personality type and a predisposition to suffer this condition. ${ }^{20,64,119,127}$ Personality traits are very stable, while anxiety, depression, and hostility can change depending on the subject's environment even if to a certain degree they are present in every person. The most accepted belief is that the distress alterations found in patients with chronic pain seem to be a consequence of the chronic pain process itself, and not the cause of it.

\subsection{Miscellaneous}

\subsubsection{Malingering}

The DSM-IV² manual defines malingering as the "the intentional production of false or grossly exaggerated physical or psychological symptoms, motivated by external incentives such as avoiding military duty, avoiding work, obtaining financial compensation, evading criminal prosecution or obtaining drugs."
From this definition, it is understood that a malicious behavior is associated with a secondary gain, but contrary to other mental processes, malingering is a deliberate behavior. This is what distinguishes it from other behaviors associated with pain and with which it should not be mistaken. Malingering is not really a psychological factor that modulates or is determined by the course of pain and disease. It is the own patient who is showing his intentions by misleading the clinicians through fictitious symptoms. Several methods to try to help the clinician in detecting patients who feign something have been developed, although they are not particularly reliable. , $^{8,2,42,67,104}$

The presence of this behavior in chronic pain patients is highly variable, ranging from $1.2 \%$ and $36 \%{ }^{3,85}$; however, other authors believe it is very low. ${ }^{76}$ Waddell ${ }^{129}$ considers that the incidence of malingering in low back pain is low, and is frequently mistaken with behaviors associated with pain.

There are no specific studies about the prevalence of malicious pretending in the AKP patient. Extrapolating results of other chronic musculoskeletal painful processes with a similar poor correlation between physical findings and radiology, we should expect to find a similar incidence of compensation to that found in low back pain patients. Possibly, this likely relationship is lower than in other chronic pain processes because the AKP patients are normally younger than those with other chronic pain from musculoskeletal conditions. Also, malingering is associated with a situation aimed at a monetary or work compensation. ${ }^{3}$

\subsubsection{Psychogenic Pain}

The concept of psychogenic pain has caused controversy in different areas of medicine not only regarding its diagnosis, but mostly regarding its existence. ${ }^{16} \mathrm{It}$ tries to explain pain when no other alterations appear in the physical examination or complementary tests. The patient with AKP seems like the perfect situation for this type of diagnosis to come up frequently. As previously explained in this chapter, psychological factors have a big influence as modulators of AKP but there is not enough evidence to state that they are the only factors present at the onset of pain. Hendler ${ }^{46}$ believes that psychogenic pain, if in fact does exist, has 
a very low prevalence ( 1 in 3,000 patients with chronic pain). Manchikanti, ${ }^{77}$ after reviewing psychological aspects of chronic pain, states that psychogenic pain is an illusion. $\mathrm{Kuch}^{64}$ performed a systematic review, concluding there was no evidence to support the theory that chronic pain is the direct result of a previous psychiatric disorder. The fact that no structural cause can be found may certainly be frustrating for the physician, but that doesn't mean there is not one. The attribution of a psychogenic origin to a great number of AKP patients can implicitly lead to not offering them the possibility of treatment. The influence of affectivity, anxiety, mood, and cognitions with chronic pain seems clear. The relationship between psychopathology, mainly depression, seems clear as well and also bidirectional. But generally, the higher prevalence of psychiatric conditions in chronic musculoskeletal pain patients appears after the onset of the musculoskeletal condition. ${ }^{20,119}$ Kuch $^{64}$ thinks that even if the psychological condition can precede the lesion, its presence does not mean that it is the cause of the chronic pain, although it can clearly worsen the situation. To attribute pain to a psychogenic origin is as limitating as trying to understand pain from a purely structural or biologic point of view.

\subsubsection{Somatization}

A somatization disorder is a controversial condition both in its definition and on how it's applied in the clinical practice. In the AKP patients, with no structural findings in the imaging tests, this diagnosis is frequently reached, especially if there is a history of emotional distress. However, to diagnose somatization in a patient, the criteria established in the DSM-IV ${ }^{2}$ have to be met.

The prevalence of somatization in the AKP patient is unknown, although it is probably very low if we extrapolate the incidence published for somatization disorders in general that range from $0.2 \%$ to $1.5 \% .^{34,105}$

Those patients with a tendency toward somatization present themselves to the physician mainly with somatic symptoms more so than with psychosocial symptoms, hoping to get medical attention and symptomatic treatment. ${ }^{76}$ This tendency begins during childhood and persists into adulthood. These patients are very heterogeneous and present themselves with a great variety of unexplained symptoms, and come frequently to the clinics. Patients with chronic pain have higher levels of hypochondria and a tendency toward somatization compared with the pain-free population..$^{29}$ It has also been stated that chronic pain patients can also confuse painful and non-painful experiences and interpret a wide variety of experiences in terms of pain, especially emotional distress and depression. ${ }^{22}$

\subsection{Conclusion}

AKP patients express chronic pain, but also disability. However, the correlation between pain and disability is not complete and linear. Some patients with a lot of pain show mild disability, while others with much less pain also show great disability. The disability is profoundly influenced by other emotional and cognitive factors that are associated with the perception of pain. Therefore, the clinical efforts do not have to be focused only on treating the pain as a feeling but on identifying and modifying these factors.

Can AKP have a psychological cause as it has been classically believed? We think not. There is a structural lesion that causes pain and disability, although sometimes it may not be found. The psychological factors modulate the course of the disease but are not the cause. Even so, psychological factors are of utmost importance, which is why it is essential that physicians be aware of them.

Even if the importance of emotion in pain and disability in AKP patients seems clear, disorders in negative emotions (anxiety and depression) are also sources of suffering in these patients and deserve to be treated independently from other measures taken in the course of the condition.

In many AKP patients, the classic biomedical approach has failed to provide adequate treatment despite decades of research. Given that the biopsychosocial model provides a better understanding of articular pain and has contributed to the improved treatment of other musculoskeletal conditions, it seem reasonable to think that a biopsychosocial approach would provide a useful tool for the conventional medical treatment of AKP. It is, therefore, interesting to contemplate cognitive-behavioral treatment models as another therapeutic option to help these patients. 


\section{References}

1. Al-Obaidi SM, Beattie P, Al-Zoabi B, et al. The relationship of anticipated pain and fear avoidance beliefs to outcome in patients with chronic low back pain who are not receiving workers' compensation. Spine. 2005;30:1051-1057.

2. American Psychiatric Association. Diagnostic and Statistical Manual for Mental Disorders. 4th ed. Arlington: American Psychiatric Association; 2000.

3. Aronoff GM, Mandel S, Genovese E, et al. Evaluating malingering in contested injury or illness. Pain Pract. 2007; 7:178-204.

4. Asmudson GJ, Norton PJ, Vlaeyen JWS. Fear avoidance models of chronic pain: an overview. In: Asmudson GJ, Vlaeyen JWS, Crombez G, eds. Understanding and Treating Fear of Pain. Oxford: Oxford University Press; 2004:3-24.

5. Astin J, Beckner W, Soeken K, et al. Psychological interventions for rheumatoid arthritis: a meta-analysis of randomized controlled trials. Arthritis Rheum. 2002;15:291-302.

6. Axford J, Heron C, Ross F, et al. Management of knee osteoarthritis in primary care: pain and depression are the major obstacles. J Psychosom Res. 2008;64:461-467.

7. Bedard GB, Reid GJ, McGrath PJ. Coping and self-medication in a community sample of junior high school students. Pain Res Manag. 1997;2:151-156.

8. Bianchini KJ, Etherton JL, Greve KW, et al. Classification accuracy of MMPI-2 validity scales in the detection of painrelated malingering: a known-groups study. Assessment. 2008; 15:435-449.

9. Borrell-Carrió F, Suchman AL, Epstein RM. The biopsychosocial model 25 years later: principles, practice, and scientific inquiry. Ann Fam Med. 2004;2:576-582.

10. Brown GK, Nicassio PM. Development of a questionnaire for the assessment of active and passive coping strategies in chronic pain patients. Pain. 1987;31:53-64.

11. Buer N, Linton SJ. Fear-avoidance beliefs and catastrophizing: occurrence and risk factor in back pain and ADL in the general population. Pain. 2002;99:485-491.

12. Butcher JN, Dahlstrom WG, Graham JR, et al. MMPI-2: Inventario Multifásico de Personalidad de Minnesota-2. Manual (spanish versión A. Avila-Espada, F. JiménezGómez). Madrid: TEA Ediciones; 1999.

13. Carlsson AM, Warner S, Mattlar CE, et al. Personality in patients with long term patellofemoral pain syndrome. Knee Surg Sports Traumatol Arthrosc. 1993;1:178-183.

14. Carragee EJ, Alamin TF, Miller JL, et al. Disographic, MRI and psychosocial determinants of low back pain disability and remission: a prospective study in subjects with benign persistent back pain. Spine J. 2005;5:24-35.

15. Clark DI, Downing N, Mitchell J, et al. Physiotherapy for anterior knee pain: a randomized controlled trial. Ann Rheum Dis. 2009;59:700-704

16. Covington EC. Psychogenic pain. What it means, why it does not exist and how to diagnose it. Pain Med. 2000;1: 287-294.

17. Crombez G, Eccleston C, Baeyens F, et al. When somatic information threatens, catastrophic thinking enhances attentional interference. Pain. 1998;75:187-198.

18. Crombez G, Vlaeyen JW, Heuts PH, et al. Pain related fear is more disabling than pain itself: evidence on the role of pain related fear in chronic low back pain disability. Pain. 1999;80:329-339.

19. De Pablos J, Farrington D (2003). La rodilla dolorosa en la infancia y la adolescencia. En La rodilla infantil, Ed: J dePablos. Argon, majadahonda. pp25-36

20. Dersh J, Gatchel RJ, Polatin P, et al. Prevalence of psychiatric disorders in patients with chronic work-related musculoskeletal pain disability. J Occup Environ Med. 2002;44: 459-468.

21. Domenech J, Sanchis-Alfonso V, Espejo B, et al. Factores psicológicos en el síndrome femoropatelar. Estudio analítico transversal. Valencia: Congreso Sociedad Española Investigación en Cirugía Ortopédica (INVESCOT); 2010.

22. Dworkin SF, Wilson L, Masson DL. Somatizing as a risk factor for chronic pain. In: Grzesiak RC, Ciccone DC, eds. Psychological Vulnerbility to Chronic Pain. New York: Springer; 1994.

23. Edward RR, Smith MT, Stonerock G, et al. Pain-related catastrophizing in healthy women is associated with greater temporal summation of and reduced habituation to thermal pain. Clin J Pain. 2006;22:730-737.

24. Edwards RR, Fillingim RB, Maixner W, et al. Catastrophizing predicts changes in thermal pain responses after resolution of acute dental pain. J Pain. 2004;5:164-170.

25. Engel George L. The need for a new medical model. Science. 1977; 196:129-136.

26. Evers AW, Kraaimaat FW, van Riel PL, et al. Tailored cognitive behavioral therapy in early rheumatoid arthritis for patients at risk: a randomised controlled trial. Pain. 2002;100:141-153.

27. Fishbain DA, Cole B, Cutler RB, et al. Chronic pain and the measurement of personality: do states influence traits? Pain Med. 2006;7:509-529.

28. Fishbain DA, Cutler R, Rosomoff HL, et al. Chronic painassociated depression: antecedent or consequence of chronic pain? A review. Clin J Pain. 1997;13:116-137.

29. Fishbain DA, Lewis JE, Gao J, et al. Is chronic pain associated with somatization/hypochondriasis? An evidence based structured review. Pain Pract. 2009;9:449-467.

30. Forsythe ME, Dumbar MJ, Henningar AW, et al. Prospective relation between catastrophizing and residual pain following knee arthroplasty: two-year follow-up. Pain Res Manag. 2008;13:335-341.

31. Foster G, Taylor SJ, Eldridge SE, et al. Self-management education programmes by lay leaders for people with chronic conditions. Cochrane Database Syst Rev. 2007;CD005108.

32. Fritz GK, Bleck EE, Dahl IS. Functional versus organic knee pain in adolescents. A pilot study. Am J Sports Med. 1981;7:247-249.

33. Fritz JM, George S, Delitto A. The role of fear avoidance beliefs in acute low back pain: relationship with current and future disability and work status. Pain. 2001;94:7-15.

34. Fynk P, Hansen MS, Oxhoj ML. The prevalence of somatoform disorders among internal medical inpatients. $J$ Psychosom Res. 2004;56:413-418.

35. Gatchel RJ, Garofalo JP, Ellis E, et al. Major psychological disorders in acute and chronic TMD: an initial examination. J Am Dent Assoc. 1996;127:1365-1374.

36. Gatchel RJ, Peng YB, Peters ML, et al. The biopsychosocial approach to chronic pain: scientific advances and future directions. Psychol Bull. 2007;133:581-624. 
37. Gatchel RJ, Polatin PB, Mayer TG. The dominant role of psychosocial risk factors in the development of chronic low back pain disability. Spine. 1995;20:2702-2709.

38. Geisser ME, Robinson ME, Keefe FJ, et al. Catastrophizing, depression and the sensory, affective and evaluative aspects of chronic pain. Pain. 1994;59:79-83.

39. George SZ, Fritz JM, McNeil DW. Fear avoidance beliefs as measured by the fear avoidance beliefs questionnaire: change in fear avoidance beliefs questionnaire is predictive of change in self report of disability and pain intensity for patients with acute low back pain. Clin J Pain. 2006;22: 197-203.

40. Gracely RH, Geisser ME, Giesecke T, et al. Pain catastrophizing and neural responses to pain among persons with fibromyalgia. Brain. 2004;127:835-843.

41. Granot M, Ferber SG. The roles of pain catastrophizing and anxiety in the prediction of postoperative pain intensity: a prospective study. Clin J Pain. 2005;21:439-445.

42. Grave KW, Bianchini KJ, Etherton JL, et al. Detecting malingered pain-related disability: classification accuracy of the Portland digit recognition test. Clin Neuropsychol. 2009;23:850-869.

43. Grotle M, Vollestad NK, Brox JI. Clinical course and impact of fear avoidance beliefs in acute low back pain. Spine. 2006;31:1038-1046.

44. Hagendorn SD, Maruta T, Swanson DW, et al. Premorbid MMPI profiles of low back patients. Surgical successes versus surgical failures. Clin J Pain. 1985;1:177-179.

45. Haim A, Yaniv M, Dekel S, et al. Patellofemoral pain syndrome: validity of clinical and radiological features. Clin Orthop. 2006;451:223-228.

46. Hendler N, Bergson C, Morrison C. Overlooked physical diagnoses in chronic pain patients involved in litigation, Part 2. Psychosomatics. 1996;37:509-517.

47. IASP Subcomité on Taxonomy. Pain terms: a list with definitions and notes on usage. Pain. 1979;6:247-252.

48. Jacobson NS, Butler R. Relation of cognitive coping and catastrophizing to acute pain and analgesic use following breast cancer surgery. J Behav Med. 2000;19:17-29.

49. Jensen JN, Albertsen K, Borg V, et al. The predictive effect of fear-avoidance beliefs on low back pain among newly qualified health care workers with and without previous low back pain: a prospective cohort study. BMC Musculoskelet Disord. 2009;10:117.

50. Jensen R, Hystad T, Baerheim A. Knee function and pain related to psychological variables in patients with long-term patellofemoral pain syndrome. J Orthop Sports Phys Ther. 2005;35:594-600.

51. Johnson LL, van Dyk GE, Green JR, et al. Clinical assessment of asymptomatic knees: comparison of men and women. Arthroscopy. 1998;14:347-359.

52. Karjalainenen K, Malmivaara A, Van Tulder M, et al. Multidisciplinary biopsychosocial rehabilitation for subacute low back pain among working age adults. Cochrane Database Syst Rev. 2003;(2):CD002193.

53. Keefe FJ, Affleck G, Lefebvre JC, et al. Pain coping strategies and coping efficacy in rheumatoid arthritis: a daily process analysis. Pain. 1997;69:35-42.

54. Keefe FJ, Bonk V. Valoración psicosocial del dolor en pacientes con enfermedades reumáticas. Rheuma Dis Clin North Am. 1999;1:81-104.
55. Keefe FJ, Caldwell DS, Queen KT, et al. Pain coping strategies in osteoarthritis patients. J Consult Clin Psychol. 1987;55:208-212.

56. Keefe FJ, DS C, Queen KT, et al. Osteoarthritic knee pain: a behavioural analysis. Pain. 1987;28:309-321.

57. Keefe FJ, Gk B, Wallston KA, et al. Coping with rheumatoid arthritis pain: catastrophizing as a maladaptative strategy. Pain. 1989;37:51-56.

58. Keefe FJ, Lefebvre JC, Egert JR, et al. The relationship of gender to pain, pain behavior, and disability in osteoarthritis patients: the role of catastrophizing. Pain. 2000;87:325-334.

59. Keeley P, Creed F, Tomenson B, et al. Psychosocial predictors of health-related quality of life and health service utilisation in people with chronic low back pain. Pain. 2008; $135: 142-150$.

60. Kendell K, Saxby B, Farrow M, et al. Psychological factors associated with short term recovery from total knee replacement. Br J Health Psychol. 2001;6:41-52.

61. Kinney RK, Gatchel RJ, Polatin PB, et al. Prevalence of psychopathology in acute and chronic low back pain patients. J Occup Rehabil. 1993;3:95-103.

62. Kojima M, Kojima T, Suzuki S, et al. Depression, inflammation, and pain in patients with rheumatoid arthritis. Arthritis Rheum. 2009;61:1018-1024.

63. Kroenke K, Bair MJ, Damush TM, et al. Optimized antidepressant therapy and pain self-management in primary care patients with depression and musculoskeletal pain: a randomized controlled trial. JAMA. 2009;301:2099-2110.

64. Kuch K. Psychological factors and the development of chronic pain. Clin J Pain. 2001;17:S33-S38.

65. Laín-Entralgo P. El diagnóstico Médico. Historia y Teoría. Barcelona: Salvat; 1982.

66. Lazarus R, Folkman S. Stress, Appraisal and Coping. New York: Springer; 1984.

67. Lee-Haley PR, English LT, Glenn WJ. A fake bad scale on the MMPI-2 for personal injury claimants. Psychol Rep. 1991;68:203-210.

68. Leeuw M, Goosens ME, Linton SJ, et al. The fear-avoidance model of musculoskeletal pain: current state of scientific evidence. J Behav Med. 2007;30:77-94.

69. Lethem J, Slade PD, Troup JD, et al. Outline of a fear avoidance model of exaggerated pain perception. Behav Res Ther. 1983;2:401-408.

70. Linder J, Poston WSC, Haddock CK, et al. Does personality or psychopathology predict disability in chronic pain patients. Disabil Rehabil. 2000;22:281-287.

71. Linton SJ, Boersma K, Jansson M, et al. Are fear avoidance beliefs related to the inception of an episode of back pain? A prospective study. Psychol Health. 1999;14:1051-1059.

72. Linton SJ, Boersma K, Jansson M, et al. The effects of cognitive behavioural and physical therapy preventive interventions on pain related sick leave. A randomized controlled trial. Clin J Pain. 2005;21:109-119.

73. Love PW, Peck CL. The MMPI and psychological factors in chronic low back pain. A review. Pain. 1987;28:1-12.

74. Macintyre NJ, Hill NA, Fellows RA, et al. Patellofemoral joint kinematics in individuals with and without patellofemoral pain síndrome. J Bone Joint Surg. 2006;88A:2596-2605.

75. Malmgren-Olsson EB, Bergdahl J. Temperament and character personality dimensions in patients with nonspecific musculoskeletal disorders. Clin J Pain. 2006;22:625-631. 
76. Manchikanti L, Fellows B, Pampati, et al. Comparison of psychological status of chronic pain patients and the general population. Pain Physician. 2002;5:40-48.

77. Manchikanti L, Fellows B, Singh V. Understanding psychological aspects of chronic pain in interventional pain management. Pain Physician. 2001;5:57-82.

78. Martin M, Bradley L, Alexander R, et al. Coping strategies predict disability in patients with primary fibromyalgia. Pain. 1996;68:45-53.

79. McCracken LM, Faber SD, Janeck AS. Pain-related anxiety predicts non-specific physical complaints in persons with chronic pain. Behav Res Ther. 1998;36:621-630.

80. McWilliams LA, Cox BJ, Enns MW. Mood and anxiety disorders associated with chronic pain: an examination in a nationally representative sample. Pain. 2003;106:127-133.

81. Melzack R. From the gate to the neuromatrix. Pain. 1999;6:S121-S126.

82. Melzack R, Casey KL. The Skin Senses. Springfield: CC Thomas; 1968:423-443.

83. Mercado AC, Carroll LJ, Cassidy JD, et al. Passive coping as a risk factor for disabling neck and low back pain. Pain. 2006;117:51-57.

84. Meyer K, Tschopp A, Sprott H, et al. Association between catastrophizing and self-rated pain and disability in patients with chronic low back pain. J Rehabil Med. 2009;41:620-625.

85. Novy DM, Collins HS, Nelson DV, et al. Waddell signs: distributional properties and correlates. Arch Phys Med Rehabil. 1998;79:820-822.

86. Owen-Salters E, Gatchel RJ, Polatin PB, et al. Changes in psychopathology following functional restoration of chronic low back pain patients: a prospective study. J Occup Rehabil. 1996;6:215-223.

87. Parker JC, Smarr KL, Buescher KL, et al. Pain control and rational thinking: implications for rheumatoid arthritis. Arthritis Rheum. 1989;38:1807-1818.

88. Pavlin DJ, Sullivan MJ, Freund PR, et al. Catastrophizing: a risk factor for postsurgical pain. Clin J Pain. 2005;21: 83-90.

89. Peck JR, Smith TW, Ward JR, et al. Disability and depression in rheumatoid arthritis. A multi-trait, multi-method investigation. Arthritis Rheum. 1989;32:1100-1106.

90. Perrot S, Poiraudeau S, Kabir M, et al. Active or passive pain coping strategies in hip and knee osteoarthritis? Results of a national survey of 4,719 patients in a primary care setting. Arthritis Rheum. 2008;59:1555-1562.

91. Peters ML, Vlaeyen JWS, van Drunen C. Do fibromyalgia patients display hypervigiance for innocuous somatosensory stimulus? Application of a body scanning reaction time paradigm. Pain. 2000;86:283-292.

92. Peters ML, Vlaeyen JWS, Weber WEJ. The joint contribution of physical pathology, pain-related fear and catastrophizing to chronic back pain disability. Pain. 2005;113:45-50.

93. Philips HC. Avoidance behaviour and its role in sustaining chronic pain. Behav Res Ther. 1987;25:273-279.

94. Picavet HSJ, Vlaeyen JWS, Schouten SAG. Pain catastrophizing and kinesiophobia: predictors of chronic low back pain. Am J Epidemiol. 2002;156:1028-1034.

95. Pincus T, Burton AK, Vogel S, et al. A systematic review of psychological factors as predictors of chronicity/disability in prospective cohorts of low back pain. Spine. 2002;27: 109-120.
96. Pincus T, Callahan LF, Bradley LA, et al. Elevated MMPI scores for hypochondriasis, depression and hysteria in patients with rheumatoid arthritis reflect disease rather than psychological status. Arthritis Rheum. 1986;29:1456-1465.

97. Piva SR, Fitzgerald GK, Irrgang JJ, Fritz JM, et al. Associates of physical function and pain in patients with patellofemoral pain syndrome. Arch Phys Med Rehabil. 2009;90:285-295.

98. Piva SR, Fitzgerald GK, Wisniewski S, et al. Predictor of pain and function outcome after rehabilitation in patients with patellofemoral pain syndrome. J Rehabil Med. 2009; 41:604-612.

99. Rosenstiel AK, Keefe FJ. The use of coping strategies in chronic low back pain patients: relationship to patient characteristics and current adjustment. Pain. 1983;17:33-44.

100. Severeijns R, Vlaeyen JW, van den Hout MA, et al. Pain catastrophizing predicts pain intensity, disability, and psychological distress independent of the level of physical impairment. Clin J Pain. 2001;17:165-172.

101. Severeijns R, Vlaeyen JWS, Van Den Hout MA, et al. Pain catastrophizing is associated with health indices in musculoskeletal pain: a cross-sectional study in the Dutch community. Health Psychol. 2004;23:49-57.

102. Sharpe L, Sensky T, Timberlake N, et al. Long-term efficacy of a cognitive behavioural treatment from a randomized controlled trial for patients recently diagnosed with rheumatoid arthritis. Rheumatology. 2003; 42:435-441.

103. Smeets RJ, Vlaeyen JW, Kester AD, et al. Reduction of pain catastrophizing mediates the outcome of both physical and cognitive- behavioral treatment in chronic low back pain. J Pain. 2006;7:261-271.

104. Smith GP, Burger GK. Detection of malingering: validation of the Structured Inventory of Malingered Symptomatology (SIMS). Am Acad Psychiatry Law. 1997;25:183-189.

105. Smith GC, Clarke DM, Handrinos D, et al. Consultationliaison psychiatrists'management of somatoforms disorders. Psychosomatics. 2000;41:481-489.

106. Soderlin MK, Hakala M, Nieminen P. Anxiety and depression in a community-based rheumatoid arthritis population. Scand J Rheumatol. 2000;29:177-183.

107. Sommers T, Keefe Fj, Pells J, et al. Pain catastrophizing and pain-related fear in osteoarthritis patients: relationships to pain and disability. J Pain Symptom Manage. 2009;37: 863-872.

108. Staiger TO, Gaster B, Sullivan MD, et al. Systematic review of antidepressants in the treatment of chronic low back pain. Spine. 2003;28:2540-2545.

109. Sullivan MJ, Adams H, Rhodenizer T, et al. A psychosocial risk factor- targeted intervention for the prevention of chronic pain and disability following whiplash injury. Phys Ther. 2006;86:8-18.

110. Sullivan HJL, Bishop SR, Pivik J. The pain catastrophizing scale: development and validation. Psychol Assess. 1995; 7:524-532.

111. Sullivan MJ, Neish N. The effects of disclosure on pain during dental hygiene treatment: the moderating role of catastrophizing. Pain. 1999;79:155-163.

112. Sullivan MJ, Rodgers WM, Wilson PM, et al. An experimental investigation of the relation between catastrophizing and activity intolerance. Pain. 2002;100:47-53. 
113. Sullivan M, Tanzer M, Stanish W, et al. Psychological determinants of problematic outcomes following total knee arthroplasty. Pain. 2009;143:123-129.

114. Sullivan MJ, Ward LC, Tripp D, et al. Secondary prevention of work disability: community-based psychosocial intervention for musculoskeletal disorders. J Оссир Rehabil. 2005; 15:377-392.

115. Swinkels-Meewise IEJ, Roelofs J, Shouten EGW, et al. Fear of movement/(re)injury predicting chronic disabling low back pain: a prospective inception cohort study. Spine. 2006;31:658-664.

116. Thomeé R, Renstrom P, Karlsson J, et al. Patellofemoral pain syndrome in young women. I. A clinical analysis of alignment, pain parameters, common symptoms and functional activity level. Scand J Med Sci Sports. 1995;5:237-244.

117. Thomeé $P$, Thomeé R, Karlsson J. Patellofemoral pain syndrome: pain, coping strategies and degree of well-being. Scand J Med Sci Sports. 2002;12:276-281.

118. Turner JA, Mancl L, Aaron LA. Pain-related catastrophizing: a daily process study. Pain. 2004;110:103-111.

119. Tyrer S. Psychosomatic pain. Br J Psychol. 2006;188:91-93.

120. Van Nieuwenhuyse A, Somville PR, Crombez G, et al. The role of physical workload and pain related fear in the development of low back pain in young workers: evidence from the BelCoBack study: results after one year of follow up. Occup Environ Med. 2006;63:247-257.

121. Varni JW, Rapoff MA, Waidron SA, et al. Effects of perceived stress on pediatric chronic pain. J Behav Med. 1996; 19:515-528.

122. Virchow R (1858) Die cellularpathologie in ihrer Begründung auf physiologische und pathologische Gewebenlehre. Berlin (accessed at http://books.google.es).

123. Vittengl JR, Clark LA, Owen-Salter E, et al. Diagnostic change and personality stability following functional restoration treatment in chronic low back pain patients. Psychol Assess. 1999;6:79-91.

124. Vlaeyen JWS, Kole Snijders AMJ, Boeren RGB, et al. Fear of movement/ (re)injury in chronic low back pain and its relation to behavioural performance. Pain. 1995;62:363-372.
125. Vlaeyen JWS, Linton SJ. Fear avoidance and its consequences in chronic musculoskeletal pain: a state of the art. Pain. 2000;85:317-332.

126. Vlaeyen JWS, Timmermans C, Rodriguez LM, et al. Catastrophic thinking about pain increases discomfort during internal atrial cardioversion. J Psychosom Res. 2004;56: 139-144.

127. Waddell G. The Back Pain Revolution. 2nd ed. London: Churchill-Livingston; 2004.

128. Waddell G, Newton M, Henderson I, et al. A fear avoidance beliefs questionnaire and the role of fear avoidance beliefs in chronic low back pain and disability. Pain. 1993;52: 157-168.

129. Waddell G, Pilowsky I, Bond MR. Clinical assessment and interpretation of abnormal illness behaviour in low back pain. Pain. 1989;39:41-53.

130. Wallis BJ, Lord SM, Bogduk M. Resolution of psychological distress of whiplash patients following treatment by radiofrequency neurotomy. A randomized double blind placebo controlled trial. Pain. 1997;73: 15-22.

131. Watkins KW, Shifren K, Park DC, et al. Age, pain, and coping with rheumatoid arthritis. Pain. 1999;82:217-228.

132. Witonski D. Anterior knee pain syndrome. Int Orthop. 1999;23:341-344.

133. Witvrouw E, Lysens R, Bellemans J, et al. Intrinsic risk factors for the development of anterior knee pain in an athletic population. A two-year prospective study. Am J Sports Med. 2000;28:480-489.

134. Woby SR, Watson PJ, Roach NK, et al. Adjustment to chronic low back pain - the relative influence of fear avoidance beliefs, catastrophizing and appraisals of control. Behav Res Ther. 2004;42:762-774.

135. Woby SR, Watson PJ, Roach NK, et al. Are changes in fear avoidance beliefs, catastrophizing and appraisal of control, predictive of changes in chronic low back pain and disability? Eur J Pain. 2004;8:201-210.

136. Zigmond AS, Snaith RP. The hospital anxiety and depression scale. Acta Psychiatr Scand. 1983;67:361-370. 